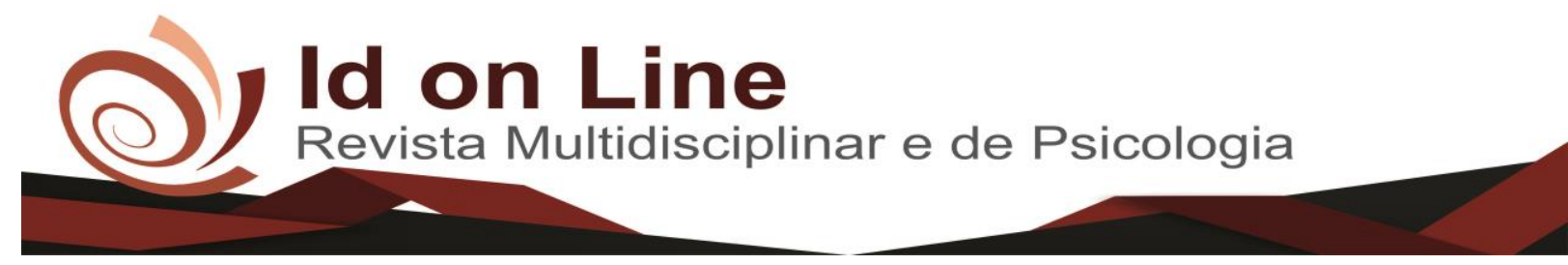

Comment

\title{
Liderança Situacional: Novo Paradigma para os Dias Atuais
}

\author{
Maria Jucicleide Lopes ${ }^{1}$; Maria Jucilene Lopes Leite ${ }^{2}$
}

\begin{abstract}
Resumo: A liderança situacional tem se constituído numa maneira eficaz de influenciar pessoas. Pode ser classificada segundo duas categorias de comportamentos: voltado para a tarefa e para a relação. objetivo principal deste estudo foi analisar os modelos de liderança quanto sua adequação para os dias contemporâneos. A investigação foi de abordagem qualitativa, do tipo exploratória, descritiva, respaldada na literatura consultada na pesquisa e com pesquisa de campo - dois estudos de caso que versam sobre a compreensão da importância do líder e o estilo adequado para o desempenho da equipe na Diretoria Cível da Comarca de Jaboatão dos Guararapes e da Escola ETE Cícero Dias, na cidade de Jaboatão dos Guararapes em Recife, respectivamente, ambos no Estado de Pernambuco, no ano de 2017. Observou-se ao final da pesquisa que foi dada ênfase a relação do Chefe-Líder com os seus subordinados identificados na doutrina, especificamente, na teoria situacional.
\end{abstract}

Palavras chave: História da Administração. Administração Pública. Gestão e Liderança.

\section{Situational Leadership: A New Paradigm for the Current Days}

\begin{abstract}
Situational leadership has been an effective way of influencing people. It can be classified according to two categories of behavior: task-oriented and for relationship. The main objective of this study was to analyze the leadership models regarding their suitability for the contemporary days. The research was qualitative, exploratory, descriptive, supported in the literature consulted in the research and field research - two case studies that deal with the understanding of the importance of the leader and the appropriate style for the team performance in the Civil Board the Jaboatão dos Guararapes district and the Cícero Dias ETE school in the city of Jaboatão dos Guararapes in Recife, both in the state of Pernambuco in the year 2017. It was observed at the end of the research that emphasis was placed on the relation of the Chief - Leader with his subordinates identified in the doctrine, specifically, in situational theory.
\end{abstract}

Keywords: History of Administration. Public administration. Management and Leadership.

\section{Introdução}

Ao longo do século XIX e XX surgiram as empresas e a moderna administração, trazendo profundas e rápidas mudanças econômicas, políticas e sociais, conhecidas como a Revolução Industrial. Nesse panorama surge Frederick W. Taylor apresentando os princípios da Administração Científica, com o

\footnotetext{
${ }^{1}$ Mestrado em Ciências da Educação.

2 Doutora em Ciências da Educação; Mestre em Ciências da Educação; Pós-Graduada em Metodologia do Ensino Superior e Gestão de Instituições Educativas; Graduada em Letras; Professora Universitária da Autarquia Educacional do Araripe AEDA. Contato: jucilenelopes@bol.com.br.
} 
objetivo de responder as necessidades da nova sociedade e suas características. Preconizava a divisão do trabalho, enfatizando tempos e métodos, seguindo os princípios da seleção científica do trabalhador, do tempo padrão, do trabalho em conjunto da supervisão e da ênfase na eficiência (CARVALHO e SAMPAIO, 2017).

\section{Chefia e liderança}

Ao longo dos anos muito foi pesquisado sobre liderança e sua definição que passa a ser mais conhecida e aceita nas organizações em geral. Conforme enfatiza Martins (2008, p. 03): "Liderança é um tema que vem sendo discutido desde os mais remotos tempos pelo homem. Ser líder, formar líderes, parece ser um desafio constante do homem e das organizações".

Surgem muitas controvérsias quando se tenta conceituar os termos chefia, liderança e gerência. Segundo alguns autores, todo chefe é um gerente, todo líder é um gerente, mesmo quanto o título "gerente" não se faça presente no nome do cargo ocupado.

A palavra gerência vem do verbo gerir, que significa administrar, dirigir, reger. Gerir uma empresa é, portanto, administrar essa empresa (ABBAGNANO, 2000). Gerir um setor dentro de uma empresa é administrar esse setor e, portanto, auxiliar na administração dessa empresa. Gerência, a partir do significado do verbo gerir, implica administração, nessa abordagem, o que caracteriza o gerente é sua função de administrador.

Chefe caracteriza-se de certa forma como um modelo antigo, pois procura no seu dia-a-dia buscar os defeitos de sua equipe para poder punir, humilhar e nas mais variadas vezes acaba destruindo o desempenho da organização, conforme diz Machado (2010, p. 04): "o chefe busca quase o tempo todo surpreender o funcionário fazendo alguma coisa errada".

Aquele que é somente chefe impõe suas ideias movidas pela autoridade, que seu cargo lhes confere, numa postura de mandante (aquele que manda) e não de comandante (aquele que comanda). Chefiar é, simplesmente, fazer um grupo funcionar para que sejam atingidos determinados objetivos (PANZENHAGEN e NEZ, 2012).

Liderar, é a habilidade de exercer influência e ser influenciado pelo grupo, através de um processo de relações interpessoais adequadas para a consecução de um ou mais objetivos comuns a todos os participantes (PANZENHAGEN e NEZ, 2012).

Machado (2010, p. 06) complementa que: "o líder tenta surpreender o colaborador fazendo alguma coisa correta. E aí ele aproveita para elevar a auto-estima da pessoa dando parabéns. Percebo ainda que sirva para fazer com que o indivíduo melhore sua criatividade". 
Liderar é, pois, um conjunto de atitudes, decisões que podem fazer de seu trabalho o reconhecimento da organização. Conforme diz Northouse (2010, p. 03): "Liderar é a arte de conduzir as pessoas para que façam o que é necessário por livre e espontânea vontade. É conseguir que seus liderados queiram fazer o que precisa ser feito".

E importante a equipe de trabalho se sentir motivada, incentivada para desenvolver um bom trabalho, pois de tudo isso depende o sucesso de uma organização que está em um mundo de transformação constante, aonde o papel do Líder vem com ênfase, para acompanhar as mudanças de hoje e também do futuro.

\section{Liderança situacional}

Com o surgimento da administração na Inglaterra no século XVIII com a Revolução Industrial e no início do século XX que os estudos científicos sustentaram a maneira correta de administrar.

Esses estudos foram formulados por Taylor, Fayol e Weber, os quais contribuíram significativamente com a Teoria da Administração, onde se tratava de aspectos e variáveis internas das organizações. (MAXIMIANO, 2000).

A liderança é indispensável em todos os tipos de organização humana e segundo Robbins (2002, p. 371), "é um processo de influência pelo qual os indivíduos, com suas ações, facilitam o movimento de um grupo de pessoas rumo a metas comuns ou compartilhadas".

De acordo com Dubrin (2003, p. 315):

Liderança é o processo de direcionar o comportamento dos outros para realização de algum objetivo. Direcionar, nesse sentido, significa fazer os indivíduos agirem de certa maneira ou seguirem um determinado curso. [...] "O foco central da liderança é conseguir que as coisas sejam realizadas pelas pessoas." (DUBRIN, 2003, p. 315).

A respeito da ação comportamental do líder e do liderado, a liderança pode ser construída. Para que isso se evidencie, é necessário destacar os três elementos básicos: distinção do observador, as expectativas do grupo e os fatos novos (REIS, 2006).

Para o estilo de liderança existem três tipos: o autocrático, o democrático e o liberal (ou laissezfaire). A primeira pesquisa que diferenciou o líder autocrático do democrático foi realizada na Iowa State University por Kurt Lewin. Posterior a essa pesquisa foi criado o modelo proposto por Tannenbaume Schimidt, onde afirmavam que a liderança era contínua e refletiam diferentes graus de participação. (DAFT, 1999).

De acordo com o modelo de Tannenbaume Schimidt, "a liderança autocrática enfatiza o comando e a ordem. Os líderes autocráticos tomam as decisões mais difíceis e dão relativamente pouca 
autoridade aos seus liderados". Neste estilo de liderança a preocupação e o interesse pelas pessoas não existia, sendo que o que mais prevalecia era o interesse pelas necessidades da organização em que lidera. (LONGENECKER, 1981, p. 204).

Na liderança democrática, a responsabilidade do líder é supervisionar com atenção as tarefas e o andamento das metas, mas com o apoio e a participação de sua equipe. Longenecker (1981, p. 204) dizia que "os líderes democráticos mostram maior deferência para com os subordinados, valorizam as ideias e sugestões dos subordinados e os consultam para garantir sua contribuição".

Assim, conceitua-se a liderança liberal de acordo com a falta de envolvimento do líder, onde não se observa ordens, não há planejamentos e nem estratégias visionárias. Sua influência é mínima em comparação com os líderes autocráticos e democráticos. Para Longenecker (1981, p. 204), "o líder do tipo laissez-faire dá um passo além e joga todo o problema ou todo o projeto nas costas do subordinado".

Com esses dois estilos de liderança e mais o liberal que representa a junção dos outros dois, Robert Tannembaume Warren Schimidt fizeram o continuum da liderança.

O modelo proposto do continuum representa uma sequência de comportamentos de liderança, que vai desde o estilo centralizado no chefe (autocrático) até o estilo centralizado no funcionário (laissez-faire). Ao escolher um desses dois comportamentos, o próximo passo é ter conhecimento de quais são as forças que estão dentro deles. Essas forças são o nível de conforto com o estilo de liderança escolhido, as forças dentro dos funcionários (prontidão para assumir responsabilidades) e as forças dentro da situação (pressões do tempo). De acordo com Tannembaume Schimidt, a sugestão seria que a melhor escolha era que os gerentes deveriam direcionar em longo prazo no sentido centralizado no funcionário, pois assim, aumentaria a qualidade do serviço, motivação, entre outros. (ROBBINS; DECENZO, 2004 p. 230).

As teorias situacionais são representadas da melhor maneira possível nas situações, como o próprio nome já diz. Esse tipo de teoria é a mais significativa para o gestor, devido apresentar opções e grandes possibilidades de mudança que podem ser adequadas ao modelo de liderança quanto às situações que podem vir a surgir.

Para Minicucci (1995, p. 297):

Esta liderança está relacionada com o seu tipo de agir, de saber quando usar tal e qual método e aprender a variar técnicas de acordo com as diferentes situações e pessoas que trabalham na equipe. Isso representa ter a sabedoria da arte de liderar. (MINICUCCI, 1995, p.297)

O conceito de liderança situacional para Stoner e Freeman (1999, p. 351):

Como dito anteriormente, a liderança situacional é uma teoria de contingência e que tem como foco os seguidores e seu nível de prontidão. Para Robbins e Decenzo (2004, p. 237) "a liderança bem-sucedida é alcançada pela seleção doestilo de liderança 
correta, a qual argumenta Hersey e Blanchard, é contingente ao nível de prontidão dos seguidores". (STONER E FREEMAN, 1999, p.351)

Essa prontidão é representada pela facilidade de realizar a tarefa que lhe foi designada ou quando mostra a intensidade e qualidade com que o liderado executa a tarefa. (HERSEY; JOHNSON, 1997 p. 289).

Para Robbins e Decenzo (2004, p. 237), "a prontidão se refere até que ponto as pessoas têm habilidade e vontade de realizar uma tarefa específica". Além da prontidão, destacam-se outros componentes na liderança situacional, os quais são elementos que caracterizam tanto os estilos do líder e do liderado. Pode-se falar em: habilidades, conhecimentos, aptidões, disposição, segurança, experiência, criatividade, desempenho, maturidade, entre outros.

Para Hersey e Johnson (1997), a liderança situacional é a melhor maneira de influenciar as pessoas, pois pode ser classificado segundo duas categorias de comportamento: o que é voltado para a tarefa e o outro para a relação. Esses dois estilos podem ser vistos em dimensões isoladas e distintas.

O comportamento voltado para a tarefa é definido pelo tempo dedicado pelo líder a explicar os deveres e as responsabilidades de uma pessoa ou de um grupo e o comportamento voltado para a relação é definido de acordo com a extensão do envolvimento do líder na comunicação bilateral ou multilateral e que abrange o ato de ouvir, facilitar e apoiar. (HERSEY; JOHNSON, 1997, p. 289)

Para a aplicação da liderança situacional nas empresas precisa-se definir o melhor estilo de liderança a ser adotado e para que isso ocorra, importantes decisões devem ser analisadas, são elas: 1) Qual o objetivo a ser alcançado? 2) Qual a prontidão do seguidor nesta situação? 3) Que ação de liderança deve ser tomada? 4) Qual foi o resultado da intervenção do líder? 5) Requer acompanhamento? Essas questões dizem respeito ao ciclo que o líder deve ter com seu liderado e só funciona quando o líder e seus seguidores entendem o modelo. (HERSEY; JOHNSON, 1997 p. 294).

De acordo com o estudo da Liderança Situacional em questão, e levando em consideração os fatores que se mostraram relevantes (motivação, comunicação, adequação às novas situações, inovação, respeito mútuo, entre outros), pode-se associá-la às empresas que adotam o estilo caórdico de Hock e onde prever que os resultados poderão ser mais evidentes.

Nessa teoria define-se maturidade como a capacidade e a disposição das pessoas de assumir a responsabilidade de dirigir seu próprio comportamento. Essas variáveis de maturidade devem ser consideradas somente em relação a uma tarefa específica a ser realizada. Quer dizer, um indivíduo ou um grupo não é maduro ou imaturo num sentido total. Todas as pessoas tendem a ser mais ou menos maduras em relação a uma tarefa, função ou objetivo específico que um líder procure realizar através dos seus esforços. 
Além de avaliar o nível de maturidade dos indivíduos dentro de um grupo, pode acontecer que o líder também tenha de avaliar o nível de maturidade do grupo como grupo, particularmente se este tiver interações frequentes na mesma área de trabalho, como ocorre com os alunos numa sala de aula.

De acordo com a Liderança Situacional, não existe um único modo melhor de influenciar as pessoas. O estilo de liderança que uma pessoa deve adotar com indivíduos ou grupos depende do nível de maturidade das pessoas que o líder deseja influenciar.

A chave da utilização da Liderança Situacional consiste em avaliar o nível de maturidade dos liderados e comportar-se de acordo com o modelo. Na Liderança Situacional está implícita a ideia de que o líder deve ajudar os liderados a amadurecer até o ponto em que sejam capazes e estejam dispostos a fazê-lo. Esse desenvolvimento dos liderados deve ser realizado ajustando-se o comportamento de liderança, ou seja, passando pelos quatro estilos ao longo da curva prescritiva.

Independentemente do nível de maturidade de um indivíduo ou grupo, podem ocorrer algumas mudanças. Sempre que, por qualquer razão, o desempenho de um liderado começar a regredir e sua capacidade ou motivação diminuir, o líder deverá reavaliar-lhe o nível de maturidade e voltar na curva prescritiva, a fim de dar-lhe o apoio sócio-emocional e a direção apropriada. Nesse ponto, porém, cumpre assinalar que a Liderança Situacional se preocupa com a adequação ou eficácia dos estilos de liderança de acordo com a maturidade dos liderados em relação à tarefa.

O objetivo deste estudo foi analisar os modelos de liderança quanto sua adequação para os dias atuais. Para isso, nos pareceu necessário também: a) Conhecer as habilidades comportamentais desenvolvidas pelo chefe-líder dentro das organizações públicas para o melhor desempenho dos seus subordinados; b) Analisar se a eficácia do líder está na combinação das variáveis na preocupação com as pessoas e a produção; c) Analisar se dentro da administração pública há mais necessidade de chefe, líder ou chefe-líder simultaneamente e; d) Sugerir qual o estilo de liderança mais adequado ao desempenho no serviço público;

\section{Metodologia}

Trata-se de uma investigação de abordagem qualitativa, do tipo exploratória, descritiva, respaldada na literatura consultada e com pesquisa de campo - dois estudos de caso que versam sobre compreensão da importância do líder e o estilo adequado para o desempenho da equipe na Diretoria Cível da Comarca de Jaboatão dos Guararapes e da Escola ETE Cícero Dias, na cidade de Jaboatão dos Guararapes e Recife, respectivamente, ambos no Estado de Pernambuco, no ano de 2017. 
A população desta investigação foi formada por 24 professores do ensino médio regular, que formam o Corpo Docente da Escola ETE Cícero Dias e 20 pessoas entre servidores e gestores da Diretoria Cível do $1^{\circ}$ grau da Comarca de Jaboatão dos Guararapes. A amostra, da escola foi 14 sujeitos da Escola ETE Cícero Dias e 16 Técnicos/Analista da Diretoria Cível. O critério para composição dessa amostra foi que participassem voluntariamente respondendo aos questionamentos propostos no questionário e que devolvessem em tempo hábil para que a pesquisa pudesse ser concluída.

Utilizou-se a técnica da entrevista aplicando como instrumento o questionário com 04 perguntas abertas e 01 fechada.

\section{Resultados e análises}

\section{Categorias de análises}

\section{Categoria 1. Habilidades comportamentais}

Analisando as habilidades comportamentais no entendimento dos técnico-analistas judiciários e professores foram feitas perguntas do tipo: O que é ser chefe? O que é ser líder? E obtiveram-se os seguintes resultados:

I - Professores: O que é ser chefe?

1. Comanda uma equipe de forma mais rígida e centralizadora (P1);

2. Manda ver como base de tudo (P2);

3. Não sou chefe (P3);

4. Os chefes são geralmente rígidos e costumam centralizar as ações, são delegadores, exigentes em resultados e controladores $(P 4)$;

5. $O$ chefe não tem legitimidade, e exerce o poder sem conhecimento e sem liderança (P5);

6. É ser temido e não respeitado. Pensamento egoísta, tendência a comandar, impor ordens e ser autoritário (P6);

7. Ser chefe é cobrar resultado dos seus subordinados sem interesse em estimulá-los. Só preocupando-se com os resultados (P7);

8. Impor normas e regras sem tentar entender a dinâmica da sua equipe de trabalho (P8);

9. É comandar, ser autoritário, dar ordens, impor, conseguir os objetivos através de intimidação e relação de subordinação da equipe (P9);

10. É quem ocupa o cargo superior, dá ordens e centraliza o poder (P10);

11. O chefe impõe é autoritário e centraliza funções. É temido, não incentiva ou motiva (P11);

12. Dar atribuições e cobrar as responsabilidades (P12);

13. Aquele que manda (P13);

14. É ser líder (P14)

II - Já os técnicos - analistas judiciários responderam:

1. É buscar otimização dos serviços internos para assim oferecer melhores serviços externos e consequentemente conquistar as metas e objetivos da organização, estejam eles voltados para o lucro ou para o serviço público (T1);

2. Aquele que comanda pessoas, impõe ordens e é autoritário (T2); 
3. Acredito que chefe e líder é a pessoa designada para gerir uma equipe, contudo, o que diferencia um do outro é a postura que esta pessoa assume. Nesse contexto, um gestor pode assumir uma postura de chefe ou líder. O chefe tem tendência a ser autoritário, individualista, não motiva ou incentiva, aponta erros e não assume responsabilidades (T3);

4. Na administração Pública ser chefe é alguém que recebeu uma delegação/título (de um superior hierárquico) com poderes para delegar, para comandar, gerir elou administrar pessoas, procedimentos ou bens materiais e imateriais (T4);

5. É importante destacar que há uma grande diferença entre ser chefe e líder, o chefe é aquela figura que não é respeitada e sim temida, pois impõe suas ordens e verdades, muitas das vezes utilizando a sua posição de poder. Embora, sendo essa a definição habitual de chefia, percebe-se nesse setor, Diretoria Cível $1^{o}$ grau do Jaboatão dos Guararapes, que as pessoas que estão à frente da equipe buscam concomitantemente chefiar e liderar (T5);

6. O indivíduo que possui a função de gerir determinada unidade (T6);

7. Ser chefe é ser hierarquicamente superior em relação aos demais servidores, impondo ordens e formas de cumprir o trabalho (T7);

8. Indivíduo que recebe delegação para ordenar, organizar, distribuir e estimular a potencialização da produção (T8);

9. Acho que o termo chefe me remete aqueles chefes do passado que lideravam suas equipes por imposição, por hierarquia (T9);

10. Chefe é aquele oficialmente designado para exercer uma função de gerência numa determinada unidade (T10);

11. Diria se tratar da pessoa incumbida da missão de ditar as tarefas, da maneira como lhe fora previamente ordenado, normalmente ser refletir sobre a real necessidade, conveniência ou possibilidade de melhoria ou evolução. Trata-se de um ser quase autômato dotado da capacidade de seguir ordens sem questionamentos e, por julgar isso correto, exige dos demais a mesma postura ou perfil comportamental (T11);

12. Literalmente, para ser chefe basta ser superior hierarquicamente do que um ou mais funcionários (T12);

13. O chefe deve ser alguém imbuído de inteligência emocional, que utiliza sua posição hierárquica para extrair o melhor de cada membro de sua equipe (T13);

14. Ser chefe é quando se administra uma equipe apenas (T14);

15. Ser chefe é proporcionar a consolidação de um ambiente organizacional necessário para dinâmica de atividades que serão desenvolvidas pela equipe de trabalho com a finalidade de atender os objetivos da empresa (T15);

16. Pessoa que possui subordinado impõe e dar ordens, autoritário (T16);

\section{III - Professores: O que é ser Líder?}

1. Comanda uma equipe de forma mais democrática e participativa (P1);

2. Organiza ver como um todo $(P 2)$;

3. Não respondeu (P3);

4. Os líderes são tendentes a democracia, é participativa, motivadores e preferem manter o foco na resolução de problemas em equipe, optam pelo diálogo ao invés da punição (P4);

5. O líder tem reconhecimento, legitimidade, admiração e é um ponto de referência social (P5),

6. É ser motivador de uma equipe (vai junto), mostrando a direção que deve ser seguido. É ser respeitado e não temido (P6);

7. Inspirar sua equipe a produzir bons resultados sem uma cobrança acentuada (P7);

8. Observar, analisar e dialogar antes de qualquer ação (P8);

9. É ser motivador e não trabalha com subordinados, mas com equipe. É o oposto do chefe (P9);

10. Tem a capacidade de motivar e inspirar sua equipe, conduzindo o trabalho junto a equipe (P10);

11. O líder inspira e motiva a equipe. Ele orienta e trabalha com um time, valorizando as habilidades dos funcionários (P11);

12. Distribui as obrigações (P12);

13. O que é líder e é exemplo (P13);

14. É ser consciente em suas ações é ser ético. (14) 
IV - Já os técnicos - analistas judiciários responderam:

1. Líder é a pessoa que sabe direcionar, competências, habilidades e personalidades em prol do resultado esperado, levando em conta as peculiaridades dos seus subordinados (T1);

2. Aquele que conduz as pessoas e os inspira (T2);

3. Um gestor que assume responsabilidades, reconhece os próprios erros, constrói soluções junto com sua equipe, motiva, incentiva, valoriza, recompensa, pode ser considerado o líder (T3);

4. É uma pessoa que naturalmente consegue liderar, chefiar e gerir pessoas, ainda que não tenham uma delegação de direito para tanto. Acredito que seja um dom que uma pessoa nasce ou uma experiência que a pessoa obtém com o tempo (T4);

5. O Líder é aquela pessoa inspiradora, que motiva sua equipe e além de mostrar o caminho a ser seguido, deixa bem claro que estará junto. Ele não precisa impor seu poder, pois é visto pela equipe com bons olhos e isso já lhe rende o respeito merecido (T5);

6. O indivíduo que, por aptidão, conquista a direção de determinado grupo por meio de suas próprias atitudes (T6);

7. Ser Líder é conseguir fazer com que as pessoas ao redor interpretem o que você diz como a melhor maneira de agir (T7);

8. Indivíduo dotado de habilidades para cumprir o papel de um chefe, com uma postura diferenciada, agregadora, humanizada e que consegue fazer com que os liderados produzam motivados. Sem dúvida é uma gestão que busca tornar o esforço de todos homogêneo-uno (T8);

9. Acho que o líder está mais adequado aos dias atuais. Acho que é aquele que sabe discutir suas estratégias com o grupo e não impõe suas opiniões (T9);

10. Líder é aquele que tem naturalmente característica de liderar um grupo (T10);

11. Desde o meu ponto de vista, trata-se da pessoa capaz de motivar e inspirar outros a seguirem. Muitas vezes age de modo não convencional e em desacordo com o que se poderia chamar de sensocomum, quebrando paradigmas. Um líder tem um senso de responsabilidade mais amplo que o chefe e tem a capacidade de pôr em risco pelo bem coletivo, acreditando em si em seus ideais. O Líder se faz sentir, se faz presente e desejado. Quem o segue tende a fazê-lo por opção, por enxergar coerência, lógica, verdade e pertinência em suas ações. O líder agrega pela paixão (T11);

12. Existem, basicamente, dois tipos de liderança (imposta e conquistada). O superior hierárquico já obtém a imposta. O desafio é construir a "liderança conquistada", onde o chefe ou não (pois para ter liderança, não se faz necessário ter um cargo de chefia), tem a admiração e confiança do seu quadro de funcionários. Com esse tipo de liderança, o gestor consegue direcionar a linha de trabalho que ele acredita e torna o ambiente de trabalho fica muito mais leve e produtivo (T12);

13. Em minha opinião, o líder é aquele escolhido por determinado grupo de pessoas por ter naturalmente uma postura conciliadora e concretizadora das demandas que se apresentam (T13);

14. Ser líder é gerir uma equipe para que, mesmo em sua ausência a mesma continue funcionando perfeitamente em harmonia (T14);

15. Ser líder é assumir uma característica de sensibilizar e envolver os membros da organização no sentido de favorecer à cooperação e à responsabilidade coletiva em sintonia com o planejamento organizacional (T15);

16. Pessoa que não tem subordinado, sugere caminhos a ser seguido, possui uma equipe, compartilha com os outros (T16);

Aquele que é somente chefe impõe suas ideias movidas pela autoridade, que seu cargo lhe confere, numa postura de mandante (aquele que manda) e não de comandante (aquele que comanda).

Chefiar é, simplesmente, fazer um grupo funcionar para que sejam atingidos determinados objetivos (NEZ, 2008).

Liderar é, pois, um conjunto de atitudes, decisões que podem fazer de seu trabalho o reconhecimento da organização. Conforme diz Jordão (2010, p. 03): "Liderar é a arte de conduzir as 
pessoas para que façam o que é necessário por livre e espontânea vontade. É conseguir que seus liderados queiram fazer o que precisa ser feito".

Ao analisar as respostas dos professores e técnicos para essa categoria, observa-se que os professores foram mais enfáticos na distinção do conceito de chefe e líder, questionando inclusive a legitimidade do chefe e considerando que o líder se faz necessário para o bom andamento dos trabalhos dentro da instituição. Por sua vez os técnicos foram mais moderados na sua distinção mais demonstraram também que a postura antiga, fechada e autoritária do chefe não é mais compatível as novas exigências, que requer uma maior maleabilidade, interação, respeito e motivação, habilidades encontradas no líder, se fazendo essencial para o bom desempenho da equipe.

\section{Categoria 2. Eficácia do líder}

Analisando a eficácia do líder no entendimento dos técnico-analistas judiciários e professores foi feita pergunta do tipo: Quais as características que você considera importante da Chefia e Liderança?

\section{I - Os professores responderam:}

1. Chefia: cobra resultados, manda fazer, delega de forma arbitrária, é autoritário. Líder: motiva a equipe, orienta e faz junto, é democrático, é firme e participativo (P1);

2. Chefia: manda, triângulo, um sobre todos, escala de ordem. Líder organiza círculo, todos sobre um, não tem escala de ordem (P2);

3. Chefia: não respondeu. Líder não respondeu (P3);

4. Chefia: centralizador, punitivos, autoritários, firmes. Líderes descentralizadores, abertos ao diálogo, democráticos, maleáveis (P4);

5. Chefia é sinônimo de patrão e de colonialidade. Líder cativa envolve e desenvolve o espírito altruísta (P5);

6. Chefia manda, fiscaliza, desmoraliza, inspira medo, somente eu. Líder orienta, confia, assume a responsabilidade, gera entusiasmo, somente nós (P6);

7. Chefia: exigente, autoritário. Líder carisma, inspirador (P7);

8. Chefia: atitude, autoritário, Eu, aponta culpados. Líder analisar, companheiro, nós, assume responsabilidade (P8);

9. Chefia não respondeu. Líder mediador, sensibilidade, proativismo, motivador, articulador, conhecimento, partilhar, democrático, saber ouvir (P9);

10. Chefia autoridade. Líder Iniciativa, habilidade de lidar, com pessoas, confiança (P10);

11. Chefia estudioso, orientador. Liderança estudioso, carismático, estrategista, incentivador, procura o diálogo (P11);

12. Chefia cobrança. Líder espontaneidade (P12);

13. Chefia estar presente, respeito, organização, que ouça, administre. Líder responsabilidade, empatia, compromisso, respeito, ouça, fale (P13);

14. Chefia postura. Líder respeito (P14) 


\section{II - Já os técnicos - analistas judiciários responderam:}

1. Chefia eficiência, eficácia, efetividade, competência, habilidade, proatividade, buscar vencer paradigmas. Liderança e eficiência com planejamento emocional e prático, eficácia com paralelos às necessidades dos subordinados, efetividade com a preocupação de treinar e melhorar as habilidades de seus subordinados, competência, habilidade, proatividade, buscar vencer paradigmas, sempre com resultados e a equipe em mente (T1);

2. Chefia não respondeu. Liderança: competência, visão, trabalha em equipe, exemplo, iniciativa, resiliência, comunicação, habilidade de lidar com as pessoas, paciência (T2);

3. Chefia comandar, centralizar, impor ordens. Liderança: motivador, valorizar a equipe, reconhecer os próprios erros, dividir bons resultados (T3);

4. Chefia título recebido por superior, qualquer pessoa pode receber esse título, não se exige capacidade técnica para gerir, chefe sem capacidade de liderança, tende a frustrar a motivação de sua delegação. Liderança é um dom nato que a pessoa tem, não é qualquer pessoa que possui, em geral desenvolvem-se com a pratica/experiência de trabalho, quando o chefe possui a capacidade de liderança, as metas objetivadas para os fins da delegação tendem a ser frutíferas (T4);

5. Chefia experiência e grandes resultados, humanidade e flexibilidade corrigiram as falhas prontamente, caráter, comunicação assertiva, respeito às regras, princípios e valores. Liderança aberto a sugestões, pronto para ajudar, planejar e traçar metas para alcançar o objetivo da equipe, buscar novos conhecimentos e experiências no ambiente interno e externo, ter poder de decisão, bom relacionamento, espírito de equipe, versatilidade, autoconhecimento (T5);

6. Chefia visão gerencial. Liderança preocupa-se com as metas e o indivíduo, participa ativamente do trabalho da equipe, é um exemplo a ser seguido pela equipe (T6);

7. Chefia competência, capacidade de se colocar no lugar do outro, equilíbrio ao exercer o poder que lhe foi dado, evitando arbitrariedades e tirania. Liderança competência, bom senso, carisma (T7);

8. Chefia fidelidade, imparcialidade, excelente nível técnico. Liderança capacidade motivadora, carisma, agregador, pacificador, imparcialidade, excelente nível técnico (T8);

9. Chefia não respondeu. Liderança sabe ouvir, suas ideias são apresentadas, sabe orientar, tem uma aptidão para gerenciar, tem empatia, defende sua equipe, tranquilidade (T9);

10. Chefia oficialidade. Liderança naturalidade (T10);

11. Chefia atuação para que todos cumpram as suas tarefas, segundo regra posta, confiança, respeito, bom relacionamento com todos, capacidade de observação e adequação de talentos a diferentes funções, capacidade motivacional e de engajamento da equipe, compreensão quanto as diferenças de obtenção do resultado pretendido, inspirar o desejo de alcançar as metas estipuladas. Liderança análise e, se necessário, proposição/criação de novas regras, confiança, respeito, bom relacionamento com todos, capacidade de observação e adequação de talentos à diferentes funções, se possível, capacidade motivacional e de engajamento da equipe, compreensão quanto as diferenças individuais, extraindo o melhor possível de cada indivíduo para a obtenção do resultado pretendido, inspirar o desejo de alcançar não apenas as metas estipuladas, mas outros objetivos, diversos e ou maiores que os estipulados (T11);

12. Chefia perseverança, compreensão, resiliência, capacidade de persuasão. Liderança perseverança, compreensão, resiliência, capacidade de persuasão, empatia (T12);

13. Chefia inteligência emocional, postura conciliadora, postura concretizadora, ser bom ouvinte, entender a equipe, explorar os pontos fortes de cada um em vez de destacar os pontos fracos. Liderança inteligência emocional, postura conciliadora, postura concretizadora, ser bom ouvinte, entender a equipe, explorar os pontos fortes de cada um em vez de destacar os pontos fracos (T13); 14. Chefia político, um bom administrador, autoridade poder. Liderança saber gerir uma equipe, conseguir integrar o grupo, cooperatividade, preocupação com os liderados (T14);

15.Chefia saber ouvir, ser promotor de uma boa estrutura de trabalho, analisar potencialidades $e$ dificuldades adequando-as, ser criativo, estar atento às mudanças e exigências do mundo corporativo, ter capacidade de análise estratégica de curto, médio e longo prazo para a unidade organizacional. Liderança ser um bom coordenador, buscar mobilizar equipe para atingir metas, buscar envolver equipe nos objetivos da organização, estar atento em manter a equipe em atuação, estar próximo do time, cooperando com a promoção de um bom clima organizacional (T15); 
16.Chefia pulso forte, competência total no que faz, dominar o assunto que gere, comprometido com os resultados. Liderança flexibilidade sem perder foco, acatar sugestões, reconhecimento pelo trabalho executado, comprometido com os resultados e bem estar da sua equipe (T16);

Para Katz (1955), uma liderança eficaz depende de três habilidades pessoais básicas: técnicas, humanas e conceituais. A habilidade técnica traduz o conhecimento técnico em um determinado tipo de trabalho ou atividade. A habilidade humana, por sua vez, possibilita a um líder estimular os membros de um grupo a executarem as suas atividades de forma cooperada, enfatizando as relações humanas. Já a habilidade conceitual traz a aptidão necessária para que seja possível trabalhar com ideias e conceitos para desenvolver um planejamento estratégico. Assim, de acordo com os níveis apresentados por um indivíduo para cada habilidade, ele poderá apresentar estilos de liderança distintos.

Segundo (MOREIRA, 1997), são habilidades necessárias ao líder para sua eficácia,

Também se indica a acessibilidade e controle emocional; a naturalidade e autenticidade; a compreensão da natureza humana e respeito pelo ser humano; a simpatia e lealdade; o interesse pelos outros; a habilidade em propor e estimular ideias e em ensinar; a habilidade em despertar esforços nos outros; a comunicação interpessoal; a capacidade de reflexão; a capacidade de enfrentar e resolver problemas; a empatia; a delegação, entre outras. (MOREIRA, 1997)

Para Stoner e Freeman (1999, p. 350):

As abordagens de características e a comportamental mostraram que a liderança eficaz dependia de muitas variáveis, como a cultura organizacional e a natureza das tarefas. Nenhum traço era comum a todos os líderes eficazes; nenhum estilo era eficaz em todas as situações. A abordagem contingencial é a visão de que a técnica de administração que melhor contribui para o alcance dos objetivos organizacionais pode variar em diferentes tipos de situações ou circunstâncias. (STONER E FREEMAN, 1999, P.350).

Com as respostas dadas verificaram-se que tanto os professores quanto os técnicos/analistas, demonstraram compreender o perfil do líder, objetivando a sua eficácia nas atividades desenvolvidas, sempre salientando as características citadas nas principais teorias apresentadas, o líder em sua plenitude se apresenta aberto, flexível, democrático, coeso, motivador, participativo, colaborador, orientador e outras características que são consideradas fundamentais para que no desempenho da função o líder possa ser eficaz.

\section{Categoria 3. Necessidade de chefe, líder ou chefe-líder}

Analisando a necessidade de chefe, líder ou chefe-líder no serviço público no entendimento dos técnico-analistas judiciários e professores foi feita pergunta do tipo: $\mathrm{Na}$ administração pública há necessidade de chefes e/ ou líderes? 


\section{I - Professores:}

1. Ambos, dependendo dos funcionários que comanda (P1);

2. Depende da situação (P2);

3. Não respondeu $(P 3)$;

4. Sem dúvida líderes são preferíveis (P4);

5. Para eficiência do serviço público, há a necessidade de líderes (P5);

6. Líderes (P6);

7. Acredito que líderes (P7);

8. O correto sempre são líderes, porém só encontramos chefes (P8);

9. Líderes (P9);

10. Líderes (P10);

11. Se o desejo é por um trabalho bem feito depende da equipe, mas no geral é um líder que gera resultados $(P 11)$;

12. Líder $(P 12)$;

13. Líderes (P13);

14. Lógico que sim, a estrutura de hierarquia é importante em todas as esferas de uma administração (P14);

\section{II - Já os técnicos - analistas judiciários responderam:}

1. Sim, pois em como em qualquer organização, é preciso que haja metas e objetivos que são melhores alcançadas com o direcionamento que só um chefe-líder pode oferecer (T1);

2. Líderes (T2);

3. Tendo em vista a diferença que acredito existir entre líder e chefe, entendo que a figura do líder se faz essencial no serviço público (T3);

4. Em todo ambiente de trabalho, é necessário um gestor-administrador, para montar uma estratégia de trabalho, para que a equipe de trabalho possa atingir o objetivo almejado, com qualidade e eficiência (T4);

5. Sim, pois se trata de instituições compostas por pessoas. Essas necessitam de chefia e liderança. Nesse sentido é possível afirmar que uma equipe bem liderada certamente estará satisfeita e isso refletirá nos resultados da empresa (T5);

6. $\operatorname{Sim}(T 6)$;

7. $\operatorname{Sim}(T 7)$;

8. Cada dia mais de líderes (T8);

9. Acho que de líderes (T9);

10. Sim, há necessidade de ambos. O ideal é que o chefe seja um líder, ou seja, não apenas exerça a função de gerência, mas que seja reconhecido pela unidade como líder (T10).

11. Em toda e qualquer corporação, penso eu, haverá espaço e necessidade para líderes e para chefes. Em determinados setores, como o militar, por exemplo, considero não haver espaço para a presença simultânea de líderes em todos os níveis. Alguns chefes se farão necessários ao funcionamento da engrenagem, conforme o nível ou setor. Grandes mudanças, penso, são direcionadas por grandes e verdadeiros líderes. Conforme o grau de maturidade, em termos de eficácia e eficiência do serviço, o chefe será preciso para manter o status quo. Para promover as mudanças, no entanto, será necessário o líder. Penso assim porque toda proposta de mudança enfrenta a aversão da maioria e, se não ocorre à adesão que (no geral) só um líder é capaz de motivar, não haverá mudança.

Na Administração Pública brasileira, mais do que nunca, líderes são necessários, em todos os níveis da administração impera a burocracia estúpida, medieval, cruel, anacrônica e contraproducente, na qual prevalece a presunção da má fé do cidadão usuário, perpetuando uma desconfiança quase esquizofrênica em face do cidadão/usuário que, até que possa "provar" o contrário (normalmente por meios e esdrúxulos e onerosos), é considerado culpado, errado, delinquente ou tendente a não cumprir lei. Do ponto de vista macro, portanto, para que se rompam paradigmas e se possa promover a melhoria esperada, líderes são necessários à administração pública (T11); 
12. Em todo ambiente de trabalho se faz necessária a presença de uma pessoa que tome decisões e oriente/cobre do quadro de funcionários, ou seja, um chefe elou líder. Sem essa figura, o trabalho tende a desandar (T12);

13. Creio que o chefe deveria ser escolhido dentre aqueles com espírito de liderança. Pois obedecemos aos chefes, mas seguimos os líderes (T13);

14. Creio que na administração pública sejam necessários líderes (gestores) e não simplesmente chefes para que haja interação entre os liderados a fim de que se possam atingir os objetivos propostos (T14);

15. A administração pública tem apresentado cada vez mais a necessidade de chefes e líderes na condução dos trabalhos em todos os setores, dado o panorama socioeconômico em que se encontra a sociedade, sendo mais exigente na qualidade dos serviços (T15);

16. Acredito que os dois em uma única pessoa (T16)

Analisando as respostas verificou-se que os professores em sua maioria apresentaram o líder como essencial ao bom desempenho das organizações, por sua vez os técnicos consideraram que a função de chefe e líder não deve ser dissociada, pois o serviço público necessita das duas em uma só pessoa, se adequando as situações, o seu estilo de liderança.

\section{Categoria 4. Estilo de liderança mais adequado}

Analisando o estilo de liderança mais adequado ao serviço público no entendimento dos técnicoanalistas judiciários e professores foi feita apresentação de cinco possibilidades básicas descritas pelo Grid criado por Blake; Mouton, 1987, p.14, para pontuação de 1 a 9, definindo o que os entrevistados consideram o estilo de liderança mais adequado aos dias atuais.

\section{Gráfico 1. Estilo de liderança mais adequado - Professores}

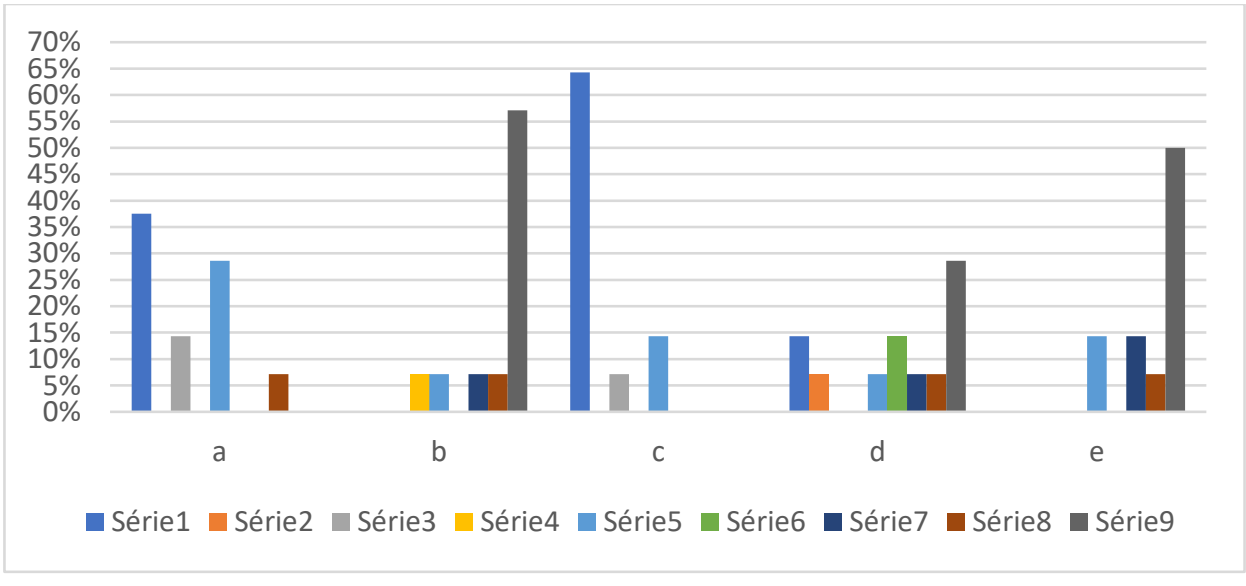

Gráfico 1. Estilo de liderança mais adequado

Fonte: autor, 2017 


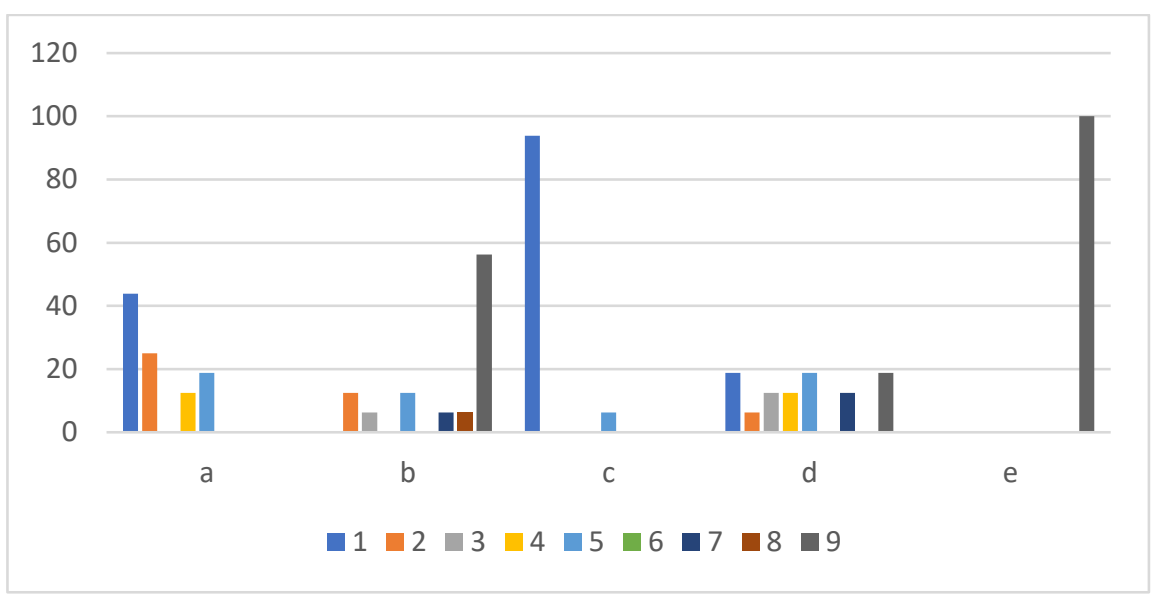

Gráfico 2. Estilo de liderança mais adequado - Técnico-analistas Fonte: autor, 2017

Os professores em sua grande maioria ao analisar o Grid (Blake, Mouton, 1987, p.14) e pontuarem, atribuíram nota máxima ao Líder-Equipe, voltado para as metas e para as pessoas, simultaneamente. Tal líder orienta-se para as metas e busca resultados de alta qualidade e em grande quantidade, mediante envolvimento, participação, comprometimento e resolução de conflitos. Já os técnicos em sua totalidade disseram considerar o estilo de liderança líder-equipe o mais adequado atribuindo a questão a nota máxima.

Esse estilo de liderança escolhido pelos entrevistados representa a ideia básica da liderança situacional que são representadas da melhor maneira possível nas situações, como o próprio nome já diz. Esse tipo de teoria é a mais significativa para o gestor, devido apresentar opções e grandes possibilidades de mudança que podem ser adequadas ao modelo de liderança quanto às situações que podem vir a surgir.

\section{Conclusões}

Com a técnica da entrevista, tendo como instrumento o questionário, buscou-se a opinião de 16 Técnicos/Analista (Estudo de Caso 1) e de 14 professores (Estudo de caso 2) que voluntariamente se dispuseram a respondê-lo, contribuindo, dessa forma, com nossa investigação.

Quanto as habilidades comportamentais desenvolvidas pelo Chefe e o Líder para o melhor desempenho das organizações públicas, especificamente na Diretoria Cível da Comarca de Jaboatão dos Guararapes e no ensino médio regular da Escola ETE Cícero Dias. Constatou-se que foi apontado que 
as habilidades dos chefes, como autoritários, centralizadores, impositivos, desmotivador e rígido, não são mais respeitados e considerados, portanto não favorecem ao crescimento e amadurecimento da equipe e não desenvolve as condições para o desempenho das organizações. Por outro lado, constatouse que o Líder foi apresentado como aquele que motiva, inspira, dialoga, orienta, valoriza, delega proativo, democrático e participativo são mais respeitados, aceitos e considerados legítimos na sua liderança. Apresentam na relação interpessoal com suas habilidades capazes de direcionar o trabalho para o efetivo desempenho das atividades e eficácia das ações planejadas.

Quanto a analisar a eficácia do líder e a combinação entre a preocupação com as pessoas e a produção, tendo em vista as extremidades como ineficazes, o grupo em sua maioria expressiva demonstrou considerar que o Líder voltado para as pessoas e metas, simultaneamente é necessário para alcançar resultados de alta qualidade e em grande quantidade, mediante envolvimento, participação, comprometimento e resolução de conflitos, assim como demonstraram considerar importante para estabelecer boas relações interpessoais, promovendo bons sentimentos entre toda equipe.

Sobre a necessidade de chefes, de líderes ou chefes/líderes e conforme já haviam feito a explanação da visão que tinham das características que tinham do chefe e do líder, a grande maioria da Diretoria Cível $1^{\circ}$ grau da Comarca de Jaboatão apontou que era necessário as duas funções simultaneamente chefe/líder para um melhor desempenho dos subordinados, ajustando a cada situação determinadas posturas que teriam uma resposta mais positiva e imediata, não considerando negativas e desnecessárias todas as habilidades do chefe, mas adaptando a cada ocasião posicionamentos que melhor alcançaria os objetivos planejados. O estudo de caso 2 da escola ETE Cícero Dias, foi observado que a grande maioria considera necessária somente a presença do líder como condutor do processo de desempenho das atividades e ainda que, a postura do chefe foi considerada na sua maioria negativa e desnecessária causando danos e enfraquecendo as relações interpessoais e consequentemente ao sucesso do desempenho das ações planejadas.

Quanto a saber qual o estilo de liderança considerado mais adequado ao desempenho no serviço público e nas respostas das diversas perguntas do questionário, observou-se que todos consideram que o líder deverá estabelecer uma relação de empatia, inspiração, confiança, orientação, delegação e motivação com seus subordinados, reconhecendo a importância das relações interpessoais tanto quanto o desempenho nas tarefas, se adequando as situações, conforme elas vão surgindo. Portanto, não se trata de apontar o melhor estilo, mas o estilo mais eficaz para uma determinada situação, pois vários estilos de comportamento do líder podem ser eficazes ou ineficazes, dependendo dos elementos importantes da situação e da aplicação correta das habilidades do líder. 


\section{Conclusões}

Conclui-se que conforme se apresentaram as respostas dadas ao questionário, observou-se que foi dada ênfase a relação do Chefe-Líder com os seus subordinados, identificando na doutrina, especificamente, na teoria situacional, que os chefes-líderes devem ser capazes de identificar a realidade do seu ambiente. Mas mesmo tendo uma boa habilidade de diagnósticos, os líderes não serão eficazes se não souberem adaptar seu estilo de liderança às exigências do ambiente. Pois o Líder deve ter a flexibilidade pessoal e a gama de habilidades necessárias para variar seu comportamento, se as necessidades e motivos dos seus subordinados forem diferentes, devem ser tratados de modo diferente.

\section{Referências}

BAGNANO, Nicola. Dicionário de Filosofia. São Paulo: Martins Fontes, 2000.

CARVALHO, Fernanda Quadros e SAMPAIO, Dilcékia Almeida. A Administração Pública: uma análise de sua história, conceitos e importância. Publicado no site: Net Saber Artigos.http://artigos.netsaber.com.br/resumo_artigo_40824/artigo_sobre_a_administracao_publica:_u ma_analise_de_sua_historia,_conceitos_e_importancia. Acessado em 03/11/2017.

DAFT, R. Teoria e projeto organizacional. São Paulo: LTC, 1999.

DUBRIN, Andrew J. Fundamentos do Comportamento Organizacional. Encontro Internacional sobre Aprendizagem Significativa, 1997, Burgos, Espanha. Actas.Burgos: ENAS, 1997.

HERSEY P, JOHNSON DE Liderança situacional na organização multicultural. In: Hesselbein F, Goldsmith M, Beckard R, organizadores. A organização do futuro. São Paulo (SP): Futura; 1997.

JORDÃO, Clarissa Menezes. ILA - ILF - ILE - ILG:Quem dá conta? , RBLA - Belo Horizonte, v. 14 , n. 1, p. 13-40, 2014

LONGENECKER, J. G. Introdução à administração. São Paulo:Atlas, 1981

MACHADO, A. Líder X Chefe. 2010. Disponível em: <http://www.administradores.com.br/artigos/negocios/lider-X-chefe/31055/>. Acesso em: 13 nov. 2017.

MARTINS, Manoel Henrique. Breve histórico da Administração Pública, como campo do conhecimento - Parte 1. 2008. Disponível em:http://www.gestaopublica.net/blog/?p=58.

MAXIMIANO, Antonio César Amaru. Introdução à administração. 5. ed. São Paulo: Atlas, 2000

MINICUCCI, Agostinho. Psicologia Aplicada à Administração. 5. ed. São Paulo: Atlas, 1995.

MOREIRA, M. A. Aprendizagem significativa: um conceito subjacente. In: 
Encontro Internacional sobre Aprendizagem Significativa, 1997, Burgos, Espanha. Actas.Burgos: ENAS, 1997.

NEZ, E. Desenvolvimento de liderança no serviço público. Colider: 2008 (mimeo).

NORTHOUSE, P. G. Leadership theory and practice. SAGE Publications, 2010.

PANZENHAGEN Liane Margareth e NEZ, Egeslaine de. Chefia e Liderança na Gestão: Algumas reflexões. Autorias: Curso de Pós-Graduação em Gestão de Pessoas da Faculdade SINOP-FASIPE em Sinop/MT.

http://www.unifia.edu.br/revista_eletronica/revistas/gestao_foco/artigos/ano2012/chefia_lideranca.pdf

ROBBINS SP, DECENZO DA. Fundamentos de administração: conceitos essenciais e aplicações. São Paulo: Prentice Hall; 2004. Comunicação e habilidades interpessoais. p. 252-79.

ROBBINS, S. P. Comportamento organizacional. 9ed. São Paulo: Prentice Hall, 2002.

STONER, James Arthur Finch; FREEMAN, R. Edward. Administração. 8 ed. Rio de Janeiro: Prentice Hall, 1999.

\section{Como citar este artigo (Formato ABNT):}

LOPES, Maria Jucicleide; LEITE, Maria Jucilene Lopes. Liderança Situacional: Novo Paradigma para os Dias Atuais. Id on Line Rev.Mult. Psic., 2018, vol.12, n.42, p. 349-366. ISSN: 1981-1179.

Recebido: 23/08/2018;

Aceito: $17 / 09 / 2018$ 